
.

\title{
Androgen deprivation and immunotherapy for the treatment of prostate cancer
}

\author{
Melissa Gamat and Douglas G McNeel \\ University of Wisconsin Carbone Cancer Center, Madison, Wisconsin, USA
}

Correspondence should be addressed D G McNeel

Email

dm3@medicine.wisc.edu

\begin{abstract}
Prostate cancer is the most common newly diagnosed malignancy in men, and the second most common cause of cancer-related death in the United States. The primary treatment for recurrent prostate cancer is androgen deprivation, and this therapy is typically continued lifelong for patients with metastatic prostate cancer. Androgens and androgen deprivation have profound effects on the immune system, a finding that has become more appreciated in an era where immune-based treatments for cancer are being increasingly explored. Preclinical studies suggest that androgen deprivation could potentially positively or negatively affect the use of approved immunotherapies, or those that are being developed for the treatment of prostate cancer. In this review, we provide a brief overview of the different types of androgen deprivation treatments used in the management of prostate cancer, discuss their effects on prostate tumors and the immune system and how they are being explored in combination with immunotherapy. Finally, we address some of the critical questions in the field that must be answered to identify the best approaches to combine androgen deprivation with immunotherapy for the treatment of prostate cancer.
\end{abstract}
Key Words
- androgen deprivation
- immunotherapy
- vaccine
- prostate cancer

\section{Introduction}

Prostate cancer is the most common cancer in men, and the second most common cause of cancer death in men in the United States (Siegel et al. 2016). Androgen deprivation therapy (ADT), using surgical or chemical castration, is a standard treatment used in all stages of recurrent prostate cancer. Eventually, patients will develop castrationresistant prostate cancer (CRPC) prompting additional therapies, many of which further block the androgen axis. This underscores the importance of androgens and the androgen signaling pathway in disease progression. Although ADT affects prostate tumor cells directly, there is growing evidence that androgens and androgen deprivation also have profound effects on the immune system. Immunotherapy (that involves mobilizing the immune system to attack tumor cells) has been gaining momentum as an exciting new treatment option. The first FDA-approved immunotherapy for prostate cancer, sipuleucel-T (sip-T), has highlighted the potential use of immunotherapy to improve survival for patients with advanced, metastatic prostate cancer. Other types of immune therapy, notably checkpoint inhibitor therapies targeting CTLA-4, PD-1 and PD-L1, have been approved for the treatment of many other types of cancer and are being explored as treatments for prostate cancer. It has been evident that ADT in and itself has immunomodulatory effects, and given the prevalent usage of ADT as a treatment for progressing and/or metastatic prostate cancer, it is timely to examine how ADT can affect the immune system and potentially

This paper forms part of a special section on Immunotherapy and Cancer. The guest editors for this section were Joanne Y Y Ngeow and Laura S Ward. 
be used with these immunotherapy approaches. In this review, we will explore the immunomodulatory effects of $\mathrm{ADT}$ and the rational combinations with immune therapies for prostate cancer.

\section{Role of androgens in prostate cancer}

Prostate cancer disease progression is initiated by the formation of prostatic intraepithelial neoplasia (PIN), which can progress to high grade PIN (HG-PIN), followed by adenocarcinoma (as characterized by invasion of the epithelium into the stroma) and metastasis. The prostate is heavily reliant on androgen for growth and function, and treatments targeting production of androgen or the AR itself are used in every stage of prostate cancer disease progression. Metastatic prostate cancer is the lethal phenotype of the disease and is typically treated with chronic androgen deprivation, usually by pharmacological means. Castration induces involution of the prostate and decreases the size of prostatic carcinoma (Huggins et al. 1941), which forms the rationale behind androgen deprivation as a therapy. In rodent models, castration induced rapid apoptosis in the rat ventral prostate (Banerjee et al. 1995). Androgen deprivation also induces cellular senescence, a stable cell cycle arrest in response to sub-lethal stress.

Although initially highly responsive to this therapy, these cancers almost invariably become resistant and grow in a castration-resistant manner. Historically, CRPC was called hormone-insensitive, or androgenindependent prostate cancer. However, treatment with ADT can induce changes in tumor cells that allow them to grow in androgen-depleted conditions. These changes can include tumors acquiring gene amplifications of the AR (Visakorpi et al. 1995), mutations arising in the AR (Eisermann et al. 2013), activation of the AR occurring independently of androgen (Lyons et al. 2008), tumors upregulation of steroidogenic enzymes (Pfeiffer et al. 2011) including de novo intratumoral androgen synthesis from androstenedione and DHEA (Cai et al. 2011), and persistent occupation of AR on DNA binding sites independent of ligand (Decker et al. 2012).

\section{Types of androgen deprivation therapies used in the treatment of prostate cancer}

For patients with localized prostate cancer, definitive extirpative therapy includes radical prostatectomy and/or radiation therapy (either external beam or brachytherapy), delivered with or without adjuvant androgen deprivation. Despite initial success with these treatments, up to onethird of patients will have a biochemical recurrence that is characterized by rising serum PSA (Djavan et al. 2003). Patients with biochemical recurrence can then undergo $\mathrm{ADT}$, or remain in surveillance. With evidence of metastatic prostate cancer, patients are treated with androgen deprivation with or without docetaxel chemotherapy (Teo \& Scher 2015, Gravis et al. 2016), or with or without abiraterone (Fizazi et al. 2017, James et al. 2017), with the androgen deprivation continued indefinitely. At this stage, ADT can include approaches that decrease serum androgen levels by orchiectomy or by targeting gonadotrophin releasing hormone (e.g. leuprolide, goserelin, degarelix), with or without blockade of the androgen receptor with nonsteroidal anti-androgens (e.g. bicalutamide, flutamide, nilutamide).

Two FDA-approved LHRH agonists include leuprolide and goserelin, both of which are equally effective at shutting down testosterone production (Dias Silva et al. 2012). An approved LHRH antagonist that is used in the treatment of prostate cancer is degarelix. These agents work to decrease luteinizing hormone production leading to decreased gonadal production of testosterone. LHRH agonists and antagonists are considered as pharmacological alternatives to surgical castration. Despite substantially lowering serum testosterone, adrenal production of androgens can persist, and it has become clear that prostate tumors can also synthesize androgens. Hence, other therapies are typically added to further suppress androgen levels or signaling. Nonsteroidal antiandrogens include flutamide, bicalutamide, nilutamide, enzalutamide and apalutamide. These agents bind directly to the AR with the goal of blocking AR-directing signaling. Abiraterone is a potent Cyp17A1 inhibitor that results in further decreased testosterone levels by blocking androgen production in non-gonadal tissues. $5 \alpha$-reductase converts testosterone to the more potent androgen dihydrotestosterone (DHT), which binds to the AR with greater affinity compared to testosterone. Due to remaining androgenic activity from increased testosterone, $5 \alpha$-reductase inhibitors (e.g. finasteride and dutasteride) are not considered as a monotherapy in androgen deprivation treatment for prostate cancer, however, are sometimes used in combination with other therapies.

Many other AR-targeted agents are in development for the treatment of advanced, metastatic CRPC and include androgen receptor degrading agents such as galeterone, 
and agents that target the N-terminal domain of the AR such as EPI-506. These androgen pathway targeted therapies are summarized in Table 1 . One newer class includes agents (e.g. galeterone and ASC-J9) that lead to degradation of the AR. Galeterone targets the testosterone production by inhibiting Cyp17A1, competitively inhibiting the $\mathrm{AR}$, preventing $\mathrm{AR}$ binding to DNA and enhancing degradation of both wild type AR and mutant AR (Yu et al. 2014, Njar \& Brodie 2015). However, phase 3 trials of galeterone were recently halted due to the data monitoring committee determining that galeterone would not show an improvement in patient survival compared to enzalutamide. Another AR degrading compound is ASC-J9, a curcumin analog, which induces AR degradation by disrupting AR association with ARA70, a co-regulator of AR transcription (Yamashita et al. 2012) and is able to induce degradation of both wild type AR and mutant AR encoding F877L, a mutation conferring resistance to enzalutamide. This agent, although evaluated as a treatment for acne, has not yet been evaluated as a treatment for prostate cancer. Most AR-targeted agents to date have targeted the ligand-binding domain of the AR. However, another class of AR inhibitors targets the $\mathrm{N}$-terminal domain, the domain which interacts with other transcriptional regulatory proteins (e.g. EPI-001) (Myung et al. 2013). EPI-001 binds to the AF1 domain of the AR, preventing AR transactivation (Andersen et al. 2010, Myung et al. 2013, De Mol et al. 2016). Furthermore, it induced regression of CRPC xenografts in nude mice with little toxicity effects (Andersen et al. 2010). A related N-terminal AR inhibitor called EPI-506 is currently being evaluated in phase $1 / 2$ clinical trials (NCT02606123) (Andersen 2017, Antonarakis et al. 2016).

In summary, ADT results in tumor regression, through the induction of tumor cell apoptosis and senescence.
There are several ways to decrease circulating androgen levels, using either LHRH agonists or antagonists, Cyp17A1 inhibitors or compounds to target the AR itself, such as anti-androgens, AR degrading agents or compounds that use several strategies at once. Invariably, prostate tumors develop mechanisms of resistance to these various methods of ADT.

\section{Effects of androgen deprivation on immune function}

Much of the exploration of androgens on immune function came from observed sex differences in immune responses. For example, early studies demonstrated that women produce more IgM and produce more inflammatory cytokines including leptin, IL-1RA, CRP, GM-CSF and IL-5 compared to men (Butterworth et al. 1967, Furman et al. 2014). When immunized with polyvinylpyrrolidone (PVP), female mice produced significantly more antibodies as measured by antibody titer compared to males, and when male mice were castrated, they produced significantly more antibodies compared to females (Eidinger \& Garrett 1972). Lymphocytes from female mice or castrated male mice were more reactive to alloantigens compared to male lymphocytes (Weinstein et al. 1984). In addition, autoimmune diseases are more prevalent in women compared to men (Whitacre 2001). In patients with Klinefelter's syndrome, who carry the XXY sex complement and who are subsequently treated with androgen replacement therapy, there was a significant decrease in antibody production, lymphocyte numbers and CD3+, CD4+ T-cell numbers (Kocar et al. 2000). Given the sex differences in immunity, it is likely that sex steroids such as testosterone and estrogen can affect immune system function.

Table 1 Summary of the current approved and investigational androgen deprivation therapies for prostate cancer treatment.

\begin{tabular}{|c|c|}
\hline Type of ADT & Mechanism of action \\
\hline LHRH agonist & $\begin{array}{l}\text { Persistent LHRH release, leading to } \\
\text { pituitary desensitization and } \\
\text { subsequent testosterone reduction }\end{array}$ \\
\hline LHRH antagonist & Blocks the LHRH receptor \\
\hline CYP17 inhibitor & $\begin{array}{l}\text { Blocks a key biosynthetic enzyme in } \\
\text { testosterone production }\end{array}$ \\
\hline AR antagonist & $\begin{array}{l}\text { Binds the AR - competitive inhibitor for } \\
\text { androgen }\end{array}$ \\
\hline $\begin{array}{l}5 \alpha \text {-reductase } \\
\text { inhibitor }\end{array}$ & $\begin{array}{l}\text { Inhibits } 5 \alpha \text {-reductase and prevents } \\
\text { converting testosterone to DHT }\end{array}$ \\
\hline AR degrading agent & Targets the AR for degradation \\
\hline $\begin{array}{l}\mathrm{N} \text {-terminal } \mathrm{AR} \\
\text { inhibitors }\end{array}$ & Inhibits the N-terminal domain of the AR \\
\hline
\end{tabular}

\begin{tabular}{ll}
\hline Approved/investigational & Examples \\
\cline { 1 - 1 } Approved & Leuprolide, goserelin \\
Approved & $\begin{array}{l}\text { Degarelix } \\
\text { Abiraterone }\end{array}$ \\
Approved & $\begin{array}{l}\text { Flutamide, bicalutamide, } \\
\text { nilutamide, enzalutamide }\end{array}$ \\
Approved & Dutasteride, finasteride \\
Investigational & Galeterone, ASC-509 \\
Investigational & EPI-506
\end{tabular}


Sex steroids have profound effects on the immune system, as summarized in Fig. 1. Testosterone can be converted to DHT by $5 \alpha$-reductase or alternatively aromatized to estrogen, and all of which have immunomodulatory effects. The AR is expressed in the thymus in both the epithelium and in the thymocytes (that will differentiate into mature $\mathrm{T}$ cells); however, it is AR expression in the thymic epithelium that regulates thymus size (Olsen et al. 2001). Administering DHT causes involution of the thymus (Olsen \& Kovacs 2001), and conversely castration causes an increase in thymus wet weight (Sutherland et al. 2005). The decrease in wet weight of thymus, which is induced by testosterone, is mediated by the Notch ligand Delta-like 4 (Dll4) (Velardi et al. 2014).

Androgens have also been implicated in having direct negative effects on T-cell function. Treating CD4+ $\mathrm{T}$ cells with either testosterone or DHT increased the immunosuppressive cytokine IL-10 (Liva \& Voskuhl 2001). Cytolytic T-cell activity can be suppressed by regulatory CD4+ $\mathrm{T}$ cells (Treg) characterized by the expression of CD25+ Foxp3+. Culturing splenic CD4+ T cells in serial dilutions of Leydig cell conditioned media (which produce testosterone), or testosterone directly, resulted in a dose-dependent increase in the number of CD4+ CD25+Foxp3+ Tregs (Fijak et al. 2011, 2015). Furthermore, treating CD4+ T cells with Leydig cell conditioned media significantly increased the production of regulatory T-cell cytokine IL-10 whereas concurrent treatment with the anti-androgen flutamide abolished the production of IL-10, demonstrating that CD4+ CD25+ Foxp3+ Treg function is androgen dependent (Fijak et al. 2015). These results were confirmed by another investigator group, and they further showed that an androgen responsive element is located within an intron in Foxp3, suggesting that Foxp3 is regulated by androgen (Walecki et al. 2015). Interestingly, increased Tregs in the prostate is associated with reduced PSA recurrence-free survival, and significantly associated with higher tumor grade and higher Ki67 labeling in tumors (Flammiger et al. 2013). In summary, the immunosuppressive effects of testosterone may result from several factors, including thymic involution with androgen treatment, decreasing lymphocyte proliferative ability and increased Treg cell expansion and IL-10 expression.

In animal studies, supplementation of androgens may have immunosuppressive activities. Female mice infected with lymphocytic choriomeningitis virus (LCMV) and treated with DHT resulted in a decrease in

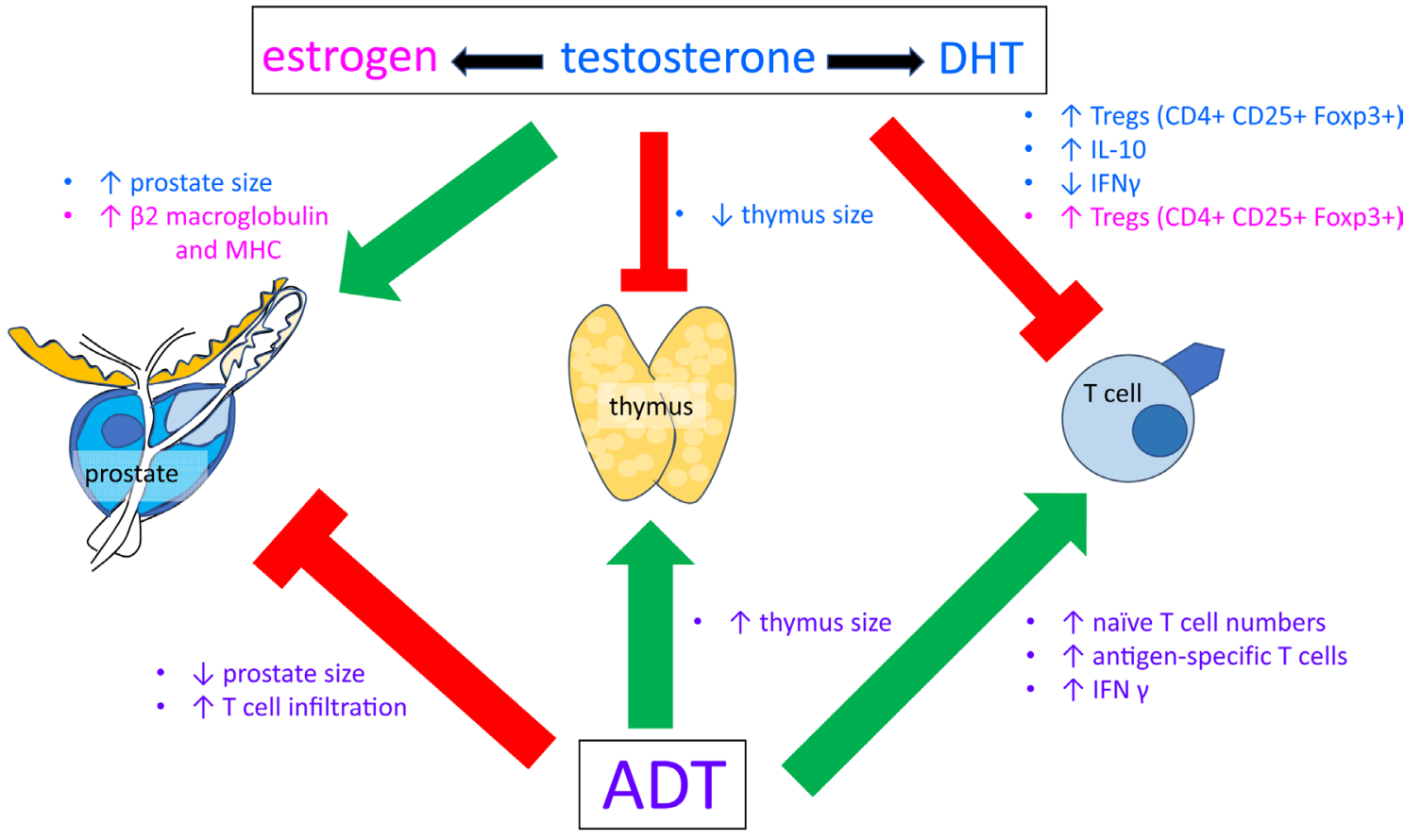

Figure 1

Sex steroids have effects on both the prostate and the thymus. Androgens such as testosterone and DHT induces a decrease in thymus weight and an increase in prostate weight. Conversely, androgen deprivation causes an increase in thymus weight and a decrease in prostate weight. Androgens also affect T cells, with testosterone causing an increase in immunosuppressive Tregs and IL-10 production and DHT causing a decrease in IFN $\gamma$-secretion by $T$ cells. In addition, estrogen causes an increase in Tregs and increased $\beta 2$-microglobulin expression and MHC molecules. Androgen deprivation causes an increase in naïve T cell numbers, increase in antigen-specific T cells and increased IFN $\gamma$ production as well as causing T-cell infiltration into the prostate. 
LCMV-specific T cells and IFN $\gamma$ production (Lin et al. 2010). In an induced mouse model of Grave's disease (an autoimmune disease), mice that were treated with DHT before induction of Grave's disease had significantly lower thyroid hormones compared to controls and significantly lower IFN $\gamma$ and IL-2 production, suggesting that DHT had an immunosuppressive effect on CD4+ $\mathrm{T}_{\mathrm{H}} 1 \mathrm{~T}$ cells (Liu et al. 2016).

The observations above suggest that androgens have immunosuppressive effects on CD4+ $\mathrm{T}_{\mathrm{H}} 1 \mathrm{~T}$ cells, which further suggests that the removal of androgens by castration should enhance immune function. Castration of aged mice caused an increase in thymus size, and this was due to increased proliferation and decreased apoptosis of thymocytes in castrated aged mice compared to intact aged mice (Sutherland et al. 2005). Castration increased absolute levels of $\mathrm{T}$ cells in the periphery (Olsen \& Kovacs 2011) and also led to increased proliferative response to antigen-specific stimulation compared to sham treatment (Roden et al. 2004, Tang et al. 2012). Mice treated with the chemotherapy agent cyclophosphamide had significantly fewer lymphocytes, but when they were castrated, they recovered lymphocytes faster compared to intact mice (Roden et al. 2004). Male mice infected with LCMV have decreased numbers of LCMV-specific T cells and IFN $\gamma$ production compared to female mice (Lin et al. 2010). However, when male mice were orchidectomized, they had increased numbers of LCMV-specific T cells and increased IFN $\gamma$ production compared to intact male mice, suggesting that testosterone decreases antigen-specific $\mathrm{T}$ cells and that ablating androgens can result in increased LCMV-specific T cells numbers (Lin et al. 2010). Treating orchidectomized mice with DHT caused a decrease in LCMV-specific T cells as well as decreased IFN $\gamma$ production. In other rodent studies, castration caused an infiltration of $\mathrm{T}$ cells into the prostate, which were initially $\mathrm{T}_{\mathrm{H}} 1$ biased, but later $\mathrm{T}_{\mathrm{H}} 17$ biased, and persisted until at least 90 days post castration (Morse \& McNeel 2012, Kissick et al. 2014). In studies of prostate tumor-bearing mice, castration with immunization similarly elicited a greater number of antigen-specific CD8+ T cells; however, an increase in Tregs was observed with prolonged treatment (Tang et al. 2012). When IL-2 was blocked, the increase in regulatory $\mathrm{T}$ cells was inhibited, suggesting that IL-2 mediates Treg expansion after castration (Tang et al. 2012). Together, all these studies demonstrate that androgen deprivation can enhance the function of T-cell.

Similar findings have been found in human studies. Androgen deprivation led to an increase in the numbers of circulating naïve $T$ cells and $T_{H} 1$-biased phenotype shortly after beginning androgen deprivation (Morse \& McNeel 2010), and decreased numbers of circulating CD4+ Treg (Page et al. 2006). In studies using short-term androgen deprivation prior to prostatectomy, an increase in oligoclonal T-cell infiltration into prostate tissue was observed (Mercader et al. 2001).

Manipulating sex hormone levels can also cause testosterone to be aromatized to estrogen, which may also have effects on the immune system. Using steroid binding assays, human CD8+ T cells were determined to express estrogen receptors (Stimson 1988), and subsequent studies using flow cytometry and immunofluorescence identified both ER $\alpha$ and ER $\beta$ present in CD4+ and CD8+ $\mathrm{T}$ cells (Pierdominici et al. 2010). In pregnant women, where there is a high estrogen environment, Tregs were significantly increased compared to that in non-pregnant women (Prieto \& Rosenstein 2006, Valor et al. 2011). Contrarily, female patients with estrogen deficiencies have been observed to have higher absolute CD8+ T-cell counts and lower CD4+ T-cell counts, together suggesting that estrogen may be involved in T-cell homeostasis (Ho et al. 1991). Moreover, treatment of prostate cancer cell lines with estrogen has been demonstrated to result in gene changes with upregulation of many genes associated with T-cell recognition, including 32 microglobulin and $\mathrm{MHC}$ molecules (Coleman et al. 2006).

In summary, androgens play a role in modulating the immune response. The sexual dimorphism in the immune response is apparent by the heightened production of antibodies and cytolytic T-cell activity in females when compared to males. Furthermore, by manipulating hormone levels through either androgen treatment or by castration, there is evidence that androgens have an immunosuppressive effect. Although castration can increase effector T-cell numbers, there can also be a concomitant increase in the number and function of Tregs. Finally, in the course of treatment with AR antagonists, patients may undergo an increase in estrogen levels due to the aromatization of testosterone, which may also have effects on T-cell homeostasis and recognition of prostate tumor cells by $\mathrm{T}$ cells.

\section{Androgen deprivation combined with immune-based treatments - preclinical studies}

Several preclinical studies have examined immune-based treatments in combination with androgen deprivation
C 2017 Society for Endocrinology Printed in Great Britain
Published by Bioscientifica Ltd 
therapies. In a study conducted by Drake and coworkwers, adoptively transferred prostate-specific CD4 T cells largely ignored the native prostate (Drake et al. 2005). However, when a tumor was present in the prostate, these transferred $\mathrm{CD} 4+\mathrm{T}$ cells underwent proliferation but were deleted later. However, castration mitigated this tolerance, permitting these cells to expand with effector function following vaccination (Drake et al. 2005). They suggested that prostate cancer immunotherapies might be most effective delivered after androgen deprivation (Drake et al. 2005). In contrast to these findings, when mice were vaccinated with DNA encoding prostate stem cell antigen (PSCA), delivered by gene gun and treated with castration either before or after vaccination, mice that were treated with vaccine first followed by castration produced significantly more PSCA-specific interferon gamma secreting T cells compared to castration followed by vaccine (Koh et al. 2009). Furthermore, they also observed that androgen ablation caused an increase in dendritic cell maturation and increased expression of costimulatory molecules, and when co-cultured with antigen-experienced T cells, induced higher expression of cytokines such as IL2, IFN $\gamma$ and TNF $\alpha$ compared to naïve $\mathrm{T}$ cells (Koh et al. 2009).

Using a Pten knockout prostate cancer mouse model, Akins and coworkers examined the effect of androgen ablation by surgical castration on infiltrating immune cells in the prostate tumor. Similar to the previous study, there was a transient increase in CD8+ cytolytic T cells and CD4+ helper T cells in the prostate 2 weeks after castration, but by 5 weeks post castration, the numbers of CD4+ or CD8+ $\mathrm{T}$ cells did not differ from pre-castration levels (Akins et al. 2010). Furthermore, granzyme B, an effector cytokine of CD8+ T cells, was significantly upregulated at 2.5 weeks after castration but decreased again by 10 weeks post castration, indicating that this cytolytictype T-cell infiltrate was not sustained. The localization of the CD8+ T cells was clustered in the stroma, rather than in the neoplastic epithelium. In addition, CD4+ CD25+ Foxp3+ Tregs were significantly increased in the tumor stroma at 2.5 weeks castration, and then throughout both the stroma and epithelium by 10 weeks post castration. Depleting Tregs, and injecting tumor cells expressing the T-cell activating TNF receptor superfamily member LIGHT (CD258) into prostate tumors as an in situ vaccination, augmented CD8+ T-cell cytolytic activity and significantly reduced prostate tumor weight, suggesting that the combination of androgen ablation, regulatory T-cell depletion and in situ vaccination was able to induce an effective anti-tumor response (Akins et al. 2010).
Ardiani and coworkers investigated a vaccine using the antigen Twist in combination with the anti-androgen enzalutamide (Ardiani et al. 2013). Twist is a basic helix-loop-helix transcription factor that is involved in epithelial-mesenchymal transition and frequently upregulated in metastatic cancer (Ansieau et al. 2010, Shiota et al. 2015). Twist expression increased as tumors progressed in the TRAMP mouse model, indicating that it is a valid tumor antigen (Ardiani et al. 2013). When enzalutamide was administered to male C57/B16 mice, there was no change in T-cell function such as proliferation or $\mathrm{CD} 4+$ effector function, but it did induce a significant decrease in genitourinary tract weight and a significant increase in thymus wet weight (Ardiani et al. 2013). Vaccinating male mice with a yeast-based vaccine encoding Twist elicited Twist-specific CD4+ T-cell proliferation, and treating male mice with enzalutamide alone also significantly increased Twist-specific CD4+ T-cell proliferation compared to control mice (Ardiani et al. 2013). However, combining Twist vaccination with enzalutamide significantly increased CD4+ T-cell proliferation compared to control or enzalutamidetreated mice. Finally, in the TRAMP model, mice treated with the combination of Twist vaccine + enzalutamide had increased overall survival compared to control mice or mice treated with monotherapy vaccine or enzalutamide alone (Ardiani et al. 2013). When Twist was incorporated into a poxviral-based vaccine and administered to agematched TRAMP mice as a monotherapy, median survival of Twist vaccinated mice was better than control mice (19 weeks vs 4 weeks, $P=0.048$ ), similar to treatment with enzalutamide vs control ( 24 weeks vs 4 weeks, $P=0.001$ ). When the Twist poxvirus vaccine was administered together with enzalutamide, overall survival was significantly better compared to either control mice or mice treated with either vaccine or enzalutamide alone (Kwilas et al. 2015). These studies indicate that combining immunotherapy with an anti-androgen can improve the anti-tumor efficacy compared to monotherapy alone. Adriani and colleagues further demonstrated that enzalutamide and abiraterone together sensitized AR-expressing prostate cancer cell lines to cytotoxic T-cell lysis (Ardiani et al. 2014). This sensitivity of CTL lysis was likely mediated by NAIP, an anti-apoptotic gene that was downregulated in LNCaP cells after treatment with either abiraterone or enzalutamide (Ardiani et al. 2014).

However, another investigator group found different results, suggesting that $\mathrm{AR}$ antagonists may have different effects compared with testosterone depletion when used in combination with immunotherapy.

Published by Bioscientifica Ltd. 
A preclinical study examined the use of a TLR9 agonist $(\mathrm{CpG})$ as an immunotherapy and the effect of tumor growth in combination with either surgical castration or leuprolide+flutamide ( $\mathrm{Pu}$ et al. 2016). Using a subcutaneous Myc-CaP cell line as a model tumor, when CpG was administered in combination with surgical orchiectomy, there was a synergistic suppression of tumor growth compared to either therapy alone. However, when CpG was administered together with ADT using leuprolide with flutamide, tumor growth was not repressed, suggesting that the immune response was repressed, likely mediated by the AR antagonist flutamide. When OVA-B16 cells were introduced to mice and treated with flutamide, there was a significant decrease in OVA antibody production and OVA-induced IFN $\gamma$ production, which was not observed in surgically orchidectomized mice. When wild type splenocytes were stimulated with anti-CD3 and anti-CD28 antibody and simultaneously treated with AR antagonists flutamide or enzalutamide, or Cyp17A1 inhibitor abiraterone, or LHRH agonist leuprolide, the AR antagonists significantly decreased IFN $\gamma$ production of both CD4+ and CD8+ T cells (Pu et al. 2016). When CpG was administered before flutamide, the repression of tumor growth was restored, suggesting that AR antagonists inhibit initial T-cell activation. Furthermore, they found that AR antagonist-induced repression of $\mathrm{T}$ cells was mediated by an off-target effect of GABA-A receptor inhibition. When CpG treatment was combined with androgen biosynthesis inhibitors such as abiraterone, the combined therapies synergized to induce near complete tumor regression. In summary, these studies demonstrate that ADT can affect the immune response generated during immunotherapy treatment. Furthermore, the type of ADT can either positively or negatively affect the immune system, although this needs to be further investigated in a systematic manner.

\section{Androgen deprivation combined with immune-based treatments - clinical trials for prostate cancer}

Cancer immunotherapy was deemed the scientific breakthrough of the year in 2013, predominantly due to the success of T-cell checkpoint inhibitors for the treatment of many different types of cancer (CouzinFrankel 2013). Despite the limited activity of these agents as monotherapies for prostate cancer, the anti-tumor vaccine Sipuleucel-T (Provenge, Dendreon Corporation) was approved for the treatment of advanced, metastatic
CRPC in 2010. Another anti-tumor vaccine, rilimogene galvacirepvec/rilimogene glafolivec (Prostvac, Bavarian Nordic) is currently in phase 3 clinical trial evaluation. Many immunotherapy agents are also being evaluated, alone or in combination, for patients with prostate cancer. Given the immunomodulatory effects of ADT, it would be rational to combine immunotherapy with ADT to augment the anti-tumor effect. Although many immune-based treatments have been evaluated in patients with advanced prostate cancer, many of whom were concurrently treated with androgen deprivation, fewer studies have specifically explored the combination of ADT with immunotherapy. In this section, we have reviewed the clinical studies that have specifically used ADT in combination with prostate cancer immunotherapies (summarized in Table 2).

As described above, the only current FDA-approved immunotherapy for prostate cancer is sipuleucel-T (sip-T), developed by Dendreon Corporation. Sip-T is an autologous cell vaccine in which peripheral blood is collected from patients, and antigen-presenting cells are activated with PA2024, a fusion protein of PAP antigen fused with GM-CSF. The activated cells are infused back into the patient where it is believed that antigen-specific activated T cells can expand to recognize and lyse tumor cells. Sip-T was approved on the basis of a randomized phase 3 trial demonstrating improved survival of patients with metastatic, CRPC treated compared to control treatment (Kantoff et al. 2010). Antigen-specific T-cell proliferation and IFN $\gamma$ secretion was significantly higher in patients treated with sip-T compared to controls (Kantoff et al. 2010, Sheikh et al. 2013). Although sip-T was approved for patients already receiving ADT, there have been two studies examining the administration of timing of ADT with sip-T. One study compared the administration of the LHRH agonist leuprolide before sip-T (ADT $\rightarrow$ sip-T) or after sip-T (sip-T $\rightarrow$ ADT) in patients with non-castrate, PSA-recurrent prostate cancer (Antonarakis et al. 2017). PA2024-specific humoral responses were significantly elevated following sip-T treatment, although there was no difference between the two arms. T-cell responses were assessed by IFN $\gamma$ ELISPOT and were similar between the groups at all time points except week 6, where there was significantly higher IFN $\gamma$ production in sip-T $\rightarrow$ ADT compared to ADT $\rightarrow$ sip-T $(P=0.013)$. Furthermore, T-cell proliferation was 2-fold higher in sip-T $\rightarrow$ ADT compared to ADT $\rightarrow$ sip-T (Antonarakis et al. 2017). The authors concluded that the timing of ADT might affect the efficacy of immunotherapy, and that a preferred sequence would be to use sip-T prior to ADT in this patient population. 
Table 2 Prostate cancer clinical trials specifically using androgen deprivation with immunotherapy.

\begin{tabular}{|c|c|}
\hline Immunotherapy & Androgen depr \\
\hline $\begin{array}{l}\text { Vaccine: Vaccinia- } \\
\text { PSA (Prostvac) }\end{array}$ & LHRH agonis \\
\hline $\begin{array}{l}\text { Vaccine: Vaccinia- } \\
\text { PSA (Prostvac) }\end{array}$ & Nilutamide \\
\hline $\begin{array}{l}\text { Vaccine: } \\
\text { Sipuleucel-T }\end{array}$ & LHRH agonis \\
\hline
\end{tabular}

$\begin{array}{ll}\begin{array}{l}\text { Vaccine: } \\ \text { Sipuleucel-T }\end{array} & \text { Abiraterone } \\ & \\ \text { Vaccine: GVAX } & \begin{array}{c}\text { LHRH antagonist } \\ \text { (degarelix) }\end{array}\end{array}$

Vaccine: pTVG-AR LHRH agonist + /bicalutamide

T-cell checkpoint Bicalutamide inhibitor:

Tremelimumab

$\begin{array}{ll}\text { T-cell checkpoint } & \text { LHRH agonist + anti- } \\ \text { inhibitor: } & \text { androgen }\end{array}$

Ipilimumab

T-cell checkpoint Enzalutamide

inhibitor:

Pembrolizumab

\begin{tabular}{ll} 
Phase & Rationale/approach \\
\cline { 1 - 1 } Phase I & $\begin{array}{c}\text { ADT used to reduce tumor burden } \\
\text { prior to vaccination }\end{array}$ \\
Phase II & $\begin{array}{c}\text { Patients with castrate-resistant } \\
\text { prostate cancer randomized to } \\
\text { Prostvac vs. nilutamide with } \\
\text { combination at progression }\end{array}$
\end{tabular}

Phase II Patients with non-castrate PSArecurrent prostate cancer randomized to sipuleucel-T followed by ADT or vice versa

Phase II Patients with MCRPC, already receiving $A D T$, randomized to receive sipuleucel-T concurrently or sequentially with abiraterone

Phase I Patients with newly diagnosed prostate cancer randomized to degarelix vs degarelix + GVAX vaccine + cyclophosphamide prior to surgery. Goal to determine if $A D T$ + vaccination can increase CD8+ $T$ cell infiltration

Phase I ADT used to reduce tumor burden, and vaccine targeting $A R$ to target AR-expressing tumor cells as mechanisms of resistance to ADT

Phase I Patients with non-castrate PSArecurrent prostate cancer received two 28-day courses of bicalutamide 3 months apart, with anti-CTLA-4 delivered at end of each cycle

Phase II Patients with recurrent prostate cancer randomized to receive ADT +/- ipilimumab

Phase II Patients with $\mathrm{MCRPC}$ and progression on enzalutamide received enzalutamide + anti-PD-1

\begin{tabular}{|c|c|}
\hline Major finding & Reference \\
\hline $\begin{array}{l}\text { Safety, } \\
\text { feasibility }\end{array}$ & $\begin{array}{l}\text { Sanda et al. } \\
\text { (1999) }\end{array}$ \\
\hline $\begin{array}{l}\text { Improved } \\
\text { survival } \\
\text { observed in } \\
\text { patients who } \\
\text { received } \\
\text { Prostvac prior } \\
\text { to nilutamide }\end{array}$ & $\begin{array}{l}\text { Arlen et al. } \\
(2005), \\
\text { Madan et al. } \\
(2008)\end{array}$ \\
\hline $\begin{array}{l}\text { Greater } \\
\text { immune } \\
\text { response } \\
\text { observed in } \\
\text { patients } \\
\text { receiving } \\
\text { sipuleucel-T } \\
\text { followed by } \\
\text { ADT }\end{array}$ & $\begin{array}{l}\text { Antonarakis } \\
\text { et al. (2017) }\end{array}$ \\
\hline $\begin{array}{l}\text { No differences } \\
\text { in immune } \\
\text { response } \\
\text { observed } \\
\text { between } \\
\text { study arms }\end{array}$ & $\begin{array}{l}\text { Small et al. } \\
\text { (2015) }\end{array}$ \\
\hline (Pending, trial & NCT01696877 \\
\hline
\end{tabular}
ongoing)

(Pending, trial

NCT02411786 ongoing)

\begin{tabular}{lc}
$\begin{array}{l}\text { Safety, } \\
\text { feasibility. }\end{array}$ & $\begin{array}{c}\text { McNeel et al. } \\
\text { (2012) }\end{array}$ \\
Prolongation & \\
of PSA & \\
doubling time & \\
in some & \\
patients & \\
0 of 112 & NCT00170157 \\
patients & \\
without & \\
progression at & \\
18 months & \\
3 of 10 patients & Graff et al. \\
with PSA & (2016) \\
reductions to & \\
$<0.2 \mathrm{ng} / \mathrm{mL}$ & \\
\hline
\end{tabular}

Another phase 2 trial examined concurrent abiraterone + prednisone with sip-T treatment vs sequential sip- $\mathrm{T} \rightarrow$ abiraterone + prednisone treatment in patients with metastatic CRPC (notably in patients already being treated with ADT), and assessed the effect on cumulative antigen-presenting cell activation (Small et al. 2015). In 69 patients treated, there was no statistically significant difference between the concurrent and sequential arm in terms of antigen-presenting cell activation, or antigenspecific T-cell proliferation and memory T-cell responses (Small et al. 2015). The study was not powered to examine whether sequential or concurrent administration of sip-T and abiraterone had any effect on clinical parameters such as PSA doubling time or overall survival; however, 
the study showed that using abiraterone did not affect the quality of sip-T manufacture.

Another vaccine that is currently undergoing phase 3 clinical trial evaluation for prostate cancer is Prostvac (Bavarian Nordic). Results from a multi-national phase 3 trial (NCT01322490) of Prostvac are expected to be released by the end of 2017. Prostvac-V/TRICOM consists of a vaccinia virus transduced to express PSA and three costimulatory molecules B7.1, ICAM-1 and LFA-3 (TRICOM) which is administered as the initial dose, followed by up to 4 boosts with Prostvac-F/TRICOM, which is a fowlpox virus transduced to express PSA and TRICOM. Preclinical studies with Prostvac in a prostatespecific PSA transgenic mouse demonstrated that the combination of Prostvac with androgen deprivation by means of castration elicited increased T-cell responses, as indicated by increased IFN $\gamma$ production and PSA-specific T cells (Arredouani et al. 2010). A phase 2 clinical study assessed the efficacy of Prostvac, and compared it to the anti-androgen nilutamide (Arlen et al. 2005). When PSA progression occurred, patients were offered the combination therapy, adding either nilutamide or vaccine to their treatment regimen. There was no significant difference in decrease in PSA between patients treated with vaccine or nilutamide, and the median time to treatment failure in the vaccine arm was 9.9 months vs 7.6 months in the nilutamide arm. In patients who had nilutamide followed by vaccine, the median time to treatment failure was 5.2 months from the start of combination therapy, whereas in patients who had vaccine followed by nilutamide, the median time to treatment failure was 13.9 months from the start of combination therapy (Arlen et al. 2005). A follow-up study after 6.5 years of initiating the therapy showed a trend for increased survival in patients randomized to the vaccine arm with a median time of 5.1 years compared to 3.4 years in the nilutamide arm, although this was not significant $(P=0.13)$ (Madan et al. 2008). When focused on the subset of patients who went from monotherapy to combination therapy, there was significantly greater survival with the vaccine first followed by nilutamide when compared to nilutamide followed by vaccine $(P=0.045)$, suggesting again that vaccine followed by an androgen receptor antagonist may be a preferred sequence of administration.

Two trials have evaluated androgen deprivation as a means to reduce prostate tumor volume prior to the use of an anti-tumor vaccine. In a small phase 1 trial of 6 patients, Sanda and coworkers evaluated Prostvac in patients with early PSA-recurrent prostate cancer after a short course of androgen deprivation (Sanda et al. 1999). More recently, we initiated a phase 1 clinical trial evaluating a DNA vaccine encoding the ligand-binding domain of the AR in patients who had started ADT within 6 months for newly metastatic disease (NCT02411786). This was based on preclinical information demonstrating that vaccination alone, targeting the AR protein itself, could prolong the survival of prostate tumor-bearing TRAMP mice, and that combining vaccination targeting the AR with ADT, could lead to a delay in castration-resistant tumor growth (Olson et al. 2013).

ADT can also potentially impact the anti-tumor efficacy of non-vaccine-based immunotherapies, notably immune checkpoint inhibitors. Several immune checkpoints that are currently approved for other cancers include ipilimumab (anti-CTLA4), tremelimumab (antiCTLA4), pembrolizumab (anti-PD1) and nivolumab (anti-PD1). Clinical trials using immune checkpoint inhibitors alone in patients with metastatic prostate cancer have been disappointing to date (Topalian et al. 2012, Kwon et al. 2014, Beer et al. 2017). A phase 1 clinical trial evaluated the combination of tremelimumab with ADT delivered in pulsatile manner in patients with biochemically recurrent disease. No favorable changes in PSA doubling time were observed shortly after the treatment, however, 3 patients experienced an increase in PSA doubling time several months after completing the treatment (McNeel et al. 2012). A randomized phase 2 clinical study specifically evaluated the combination of another CTLA4 inhibitor, ipilimumab, with ADT for patients with recurrent prostate cancer. In that trial, patients were randomized to receive LHRH agonist with an anti-androgen alone or with ipilimumab. None of the 112 patients were progression free at 18 months, the primary endpoint of the trial (NCT00170157). However, in another phase 2 trial combining pembrolizumab with enzalutamide in patients with enzalutamide-resistant disease, 4 of 20 patients achieved a PSA reduction $>50 \%$, (Graff et al. 2016). Thus, combining ADT with specific checkpoint inhibitors remains an area of interest to potentially increase the anti-tumor effectiveness of these immunotherapies.

\section{Future directions and critical questions to address over the next 5-10 years}

The fact that androgen deprivation is the primary treatment for recurrent prostate cancer, combined with its known effects on immune function, make it ideally

Published by Bioscientifica Ltc 
suited to be used in combination with existing and emerging immunotherapy treatments for prostate cancer. Notwithstanding, several critical questions remain, which should guide the next 5-10 years of research and clinical trials. First, the optimal ADTs to be used in combination are not really known, as there has been no comprehensive comparison of the various agents described above for their effects on immune function. For example, treatment with LHRH agonists results in a decrease in serum testosterone, with less effect on serum estrogen levels. Monotherapy treatment with androgen receptor agonists such as bicalutamide, however, results in increased serum testosterone and estrogen levels (Di Lorenzo et al. 2005). Treatment of prostate cancer cell lines with estrogen has been demonstrated to increase expression of MHC molecules and other molecules associated with immune recognition (Coleman et al. 2006). Hence, unopposed action of estrogen from an androgen receptor antagonist treatment, relative to LHRH agonists or agents such as abiraterone that inhibit synthesis of multiple steroid hormones, could have substantially different effects on immune function and recognition. Moreover, results by $\mathrm{Pu}$ and coworkers described above suggest that androgen receptor antagonists (flutamide and enzalutamide) can have negative effects on T-cell signaling relative to an LHRH agonist or abiraterone ( $\mathrm{Pu}$ et al. 2016). It is not known whether this is common to all androgen receptor antagonists, but again this is clearly an important area to understand the impact of all of these agents on T-cell function, antigen-presenting cell function and immune recognition of prostate tumor cells.

A second critical question is the appropriate sequence of androgen deprivation with immune-based therapies, and whether this differs depending on the type of immunotherapy approach used. Early clinical trials used androgen deprivation prior to anti-tumor vaccination in an attempt to minimize prostate tumor burden prior to vaccination (Sanda et al. 1999). In addition to minimizing tumor burden, androgen deprivation prior to anti-tumor vaccination is rational given its ability to elicit naïve $\mathrm{T}$ cells following thymic regrowth that might be primed and activated with vaccination (Morse \& McNeel 2010). Animal studies also suggested that androgen deprivation reduced tolerance to prostate-expressed antigens, further suggesting that it might best be employed prior to immunotherapy (Drake et al. 2005). However, experimental evidence from other human trials has suggested that anti-tumor vaccination may best be employed prior to androgen deprivation, using androgen deprivation to modulate the response to vaccination, rather than the reverse
(Madan et al. 2008, Antonarakis et al. 2017). The mechanism for this is not entirely understood, but may be related to changes that occur with persistent androgen deprivation. Studies in mice and rats have demonstrated that initial Th1 biased responses elicited with androgen deprivation diminish over time, and increases in Treg are observed in prostate tissue with longer term androgen deprivation (Akins et al. 2010, Morse \& McNeel 2012). Hence, immune therapies other than vaccines, perhaps those specifically targeting Treg or other tumor-regulated $\mathrm{T}$ cells, might best be used following the start of androgen deprivation. In support of this concept, a recent clinical trial has suggested that patients with advanced prostate cancer may respond to PD-1 blockade therapy when delivered with concurrent enzalutamide, despite having enzalutamide-resistant disease (Graff et al. 2016).

Related to this question of optimal sequence of androgen deprivation with immunotherapies is whether androgen deprivation might be better used as an intermittent therapy with immune-based treatments. Given concerns that continuous androgen deprivation might 'select' for castration-resistant disease, many clinical trials have been conducted to compare continuous androgen deprivation vs its use on an intermittent basis for patients with advanced prostate cancer (Alva \& Hussain 2014). The largest study powered to evaluate changes in overall survival did not demonstrate a benefit to intermittent therapy, and hence the standard of care has been to continue androgen deprivation lifelong in the setting of metastatic prostate cancer (Sciarra et al. 2013). Notwithstanding, early studies in rats have demonstrated that intermittent use of androgen deprivation elicited waves of apoptosis in prostate tissue (Sandford et al. 1984). Recent clinical trials have explored the use of intermittent androgen supplementation with androgen deprivation to more rigorously test this approach (Schweizer et al. 2016). Other rodent studies have demonstrated that the T-cell infiltrate into prostate tissue observed following short-term androgen deprivation changes over time with prolonged androgen deprivation, notably with a decrease in CD8+ T cells and an increase in Treg (Akins et al. 2010, Morse \& McNeel 2012). It remains unknown whether intermittent use of androgen deprivation might then strategically be used to maintain a CD8+ T-cell prostate tumor infiltrate, an approach that may be synergistic with immune-based treatments. One clinical trial has tested this approach using two short courses of bicalutamide and specifically sequenced with CTLA-4 blockade (McNeel et al. 2012). Although the study was too small to evaluate efficacy, the approach was found to be feasible.

Published by Bioscientifica Ltd. 
Finally, a question of major importance is whether the use of androgen deprivation with immunotherapies need be confined to evaluation in prostate cancer or could be explored for other cancers and even other immune conditions. Of note, short-term androgen deprivation has been explored in the setting of stem cell transplantation to help T-cell immune reconstitution (Sutherland et al. 2008). Hence, androgen deprivation might be used in other contexts and treatment combinations requiring an increase in naïve $\mathrm{T}$ cells. Drake and coworkers have demonstrated in mice that androgen deprivation could reduce tolerance specifically to antigens expressed by prostate tissue, enabling their recognition by subsequent immune-targeted therapy (Drake et al. 2005). Certainly the expression of prostate-expressed proteins is affected by androgen deprivation, and this may contribute to changes in the immunogenicity of prostate-expressed genes. Studies using non-prostate tumor models have similarly suggested a benefit combining androgen deprivation with tumor vaccination. However, at present it remains unknown whether the anti-tumor efficacy may be greater to antigens expressed by tissues affected by androgens or androgen deprivation.

In summary, ADT is already a standard treatment for recurrent prostate cancer. Given the systemic immunomodulatory effects of androgen deprivation with increases in thymopoiesis, and the specific effects of ADT on prostate tissue leading to cell death and infiltration by lymphocytes, combining ADT with immunotherapy is a rational direction for improving the efficacy of prostate cancer immunotherapy. Although several clinical trials have explored combination approaches, there remain critical questions related to the best androgen-targeted agents to use for combination approaches, the best sequence of these therapies and whether androgen deprivation might be better used intermittently with immunotherapy approaches. We expect these questions will guide the design of critical murine studies and clinical trials over the next $5-10$ years.

\section{Declaration of interest}

D G M has ownership interest, has received research support and serves as consultant in Madison Vaccines, Inc. M G has no relevant potential conflicts of interest.

\section{Funding}

This work is supported by the Department of Defense Prostate Cancer Research Program W81XWH-15-0492 and NIH P30 CA014520.

\section{Acknowledgements}

The authors would like to thank Dr Glenn Liu, Dr Laura Johnson and Ms Ellen Wargowski for helpful comments in this manuscript.

\section{References}

Akins EJ, Moore ML, Tang S, Willingham MC, Tooze JA \& Dubey P 2010 In situ vaccination combined with androgen ablation and regulatory T-cell depletion reduces castration-resistant tumor burden in prostate-specific pten knockout mice. Cancer Research 70 3473-3482. (doi:10.1158/0008-5472.CAN-09-2490)

Alva A \& Hussain M 2014 Intermittent androgen deprivation therapy in advanced prostate cancer. Current Treatment Options in Oncology 15 127-136. (doi:10.1007/s11864-013-0272-2)

Andersen R 2017 Sponging off nature for new drug leads. Biochemical Pharmacology 139 3-14. (doi:10.1016/j.bcp.2017.04.012)

Andersen RJ, Mawji NR, Wang J, Wang G, Haile S, Myung JK, Watt K, Tam T, Yang YC, Banuelos CA, et al. 2010 Regression of castraterecurrent prostate cancer by a small-molecule inhibitor of the amino-terminus domain of the androgen receptor. Cancer Cell $\mathbf{1 7}$ 535-546. (doi:10.1016/j.ccr.2010.04.027)

Ansieau S, Morel AP, Hinkal G, Bastid J \& Puisieux A 2010 TWISTing an embryonic transcription factor into an oncoprotein. Oncogene 29 3173-3184. (doi:10.1038/onc.2010.92)

Antonarakis ES, Chandhasin C, Osbourne E, Luo J, Sadar MD \& Perabo F 2016 Targeting the N-terminal domain of the androgen receptor: a new approach for the treatment of advanced prostate cancer. Oncologist 21 1427-1435. (doi:10.1634/theoncologist.2016-0161)

Antonarakis ES, Kibel AS, Yu EY, Karsh LI, Elfiky A, Shore ND, Vogelzang NJ, Corman JM, Millard FE, Maher JC, et al. 2017 Sequencing of sipuleucel-T and androgen deprivation therapy in men with hormone-sensitive biochemically recurrent prostate cancer: a phase II randomized trial. Clinical Cancer Research 23 2451-2459. (doi:10.1158/1078-0432.CCR-16-1780)

Ardiani A, Farsaci B, Rogers CJ, Protter A, Guo Z, King TH, Apelian D \& Hodge JW 2013 Combination therapy with a second-generation androgen receptor antagonist and a metastasis vaccine improves survival in a spontaneous prostate cancer model. Clinical Cancer Research 19 6205-6218. (doi:10.1158/1078-0432.CCR-13-1026)

Ardiani A, Gameiro SR, Kwilas AR, Donahue RN \& Hodge JW 2014 Androgen deprivation therapy sensitizes prostate cancer cells to T-cell killing through androgen receptor dependent modulation of the apoptotic pathway. Oncotarget 5 9335-9348. (doi:10.18632/ oncotarget.2429)

Arlen PM, Gulley JL, Todd N, Lieberman R, Steinberg SM, Morin S, Bastian A, Marte J, Tsang KY, Beetham P, et al. 2005 Antiandrogen, vaccine and combination therapy in patients with nonmetastatic hormone refractory prostate cancer. Journal of Urology 174 539-546. (doi:10.1097/01.ju.0000165159.33772.5b)

Arredouani MS, Tseng-Rogenski SS, Hollenbeck BK, Escara-Wilke J, Leander KR, Defeo-Jones D, Hwang C \& Sanda MG 2010 Androgen ablation augments human HLA2.1-restricted $\mathrm{T}$ cell responses to PSA self-antigen in transgenic mice. Prostate 70 1002-1011. (doi:10.1002/ pros.21134)

Banerjee PP, Banerjee S, Tilly KI, Tilly JL, Brown TR \& Zirkin BR 1995 Lobe-specific apoptotic cell death in rat prostate after androgen ablation by castration. Endocrinology 136 4368-4376. (doi:10.1210/ endo.136.10.7664656)

Beer TM, Kwon ED, Drake CG, Fizazi K, Logothetis C, Gravis G, Ganju V, Polikoff J, Saad F, Humanski P, et al. 2017 Randomized, double-blind, phase III trial of ipilimumab versus placebo in asymptomatic or minimally symptomatic patients with metastatic chemotherapy-naive castration-resistant prostate cancer. Journal of Clinical Oncology 35 40-47. (doi:10.1200/JCO.2016.69.1584)

Published by Bioscientifica Ltc. 
Butterworth M, McClellan B \& Allansmith M 1967 Influence of sex in immunoglobulin levels. Nature 214 1224-1225. (doi:10.1038/2141224a0)

Cai C, Chen S, Ng P, Bubley GJ, Nelson PS, Mostaghel EA, Marck B, Matsumoto AM, Simon NI, Wang H, et al. 2011 Intratumoral de novo steroid synthesis activates androgen receptor in castrationresistant prostate cancer and is upregulated by treatment with CYP17A1 inhibitors. Cancer Research 71 6503-6513. (doi:10.1158/0008-5472.CAN-11-0532)

Coleman IM, Kiefer JA, Brown LG, Pitts TE, Nelson PS, Brubaker KD, Vessella RL \& Corey E 2006 Inhibition of androgen-independent prostate cancer by estrogenic compounds is associated with increased expression of immune-related genes. Neoplasia 8 862-878. (doi:10.1593/neo.06328)

Couzin-Frankel J 2013 Breakthrough of the year 2013. Cancer immunotherapy. Science 342 1432-1433. (doi:10.1126/ science.342.6165.1432)

De Mol E, Fenwick RB, Phang CT, Buzon V, Szulc E, de la Fuente A, Escobedo A, Garcia J, Bertoncini CW, Estebanez-Perpina E, et al. 2016 EPI-001, a compound active against castration-resistant prostate cancer, targets transactivation unit 5 of the androgen receptor. ACS Chemical Biology 11 2499-2505. (doi:10.1021/acschembio.6b00182)

Decker KF, Zheng D, He Y, Bowman T, Edwards JR \& Jia L 2012 Persistent androgen receptor-mediated transcription in castrationresistant prostate cancer under androgen-deprived conditions. Nucleic Acids Research 40 10765-10779. (doi:10.1093/nar/gks888)

Di Lorenzo G, Perdona S, De Placido S, D'Armiento M, Gallo A, Damiano R, Pingitore D, Gallo L, De Sio M \& Autorino R 2005 Gynecomastia and breast pain induced by adjuvant therapy with bicalutamide after radical prostatectomy in patients with prostate cancer: the role of tamoxifen and radiotherapy. Journal of Urology 174 2197-2203. (doi:10.1097/01.ju.0000181824.28382.5c)

Dias Silva E, Ferreira U, Matheus W, Faria EF, Silva GD, Saito M, de Souza AA, Laranjo A Jr, Clark O, Magna LA, et al. 2012 Goserelin versus leuprolide in the chemical castration of patients with prostate cancer. International Urology and Nephrology 44 1039-1044. (doi:10.1007/s11255-012-0134-z)

Djavan B, Moul JW, Zlotta A, Remzi M \& Ravery V 2003 PSA progression following radical prostatectomy and radiation therapy: new standards in the new Millennium. European Urology 43 12-27. (doi:10.1016/S0302-2838(02)00505-5)

Drake CG, Doody AD, Mihalyo MA, Huang CT, Kelleher E, Ravi S, Hipkiss EL, Flies DB, Kennedy EP, Long M, et al. 2005 Androgen ablation mitigates tolerance to a prostate/prostate cancer-restricted antigen. Cancer Cell 7 239-249. (doi:10.1016/j.ccr.2005.01.027)

Eidinger D \& Garrett TJ 1972 Studies of the regulatory effects of the sex hormones on antibody formation and stem cell differentiation. Journal of Experimental Medicine 136 1098-1116. (doi:10.1084/ jem.136.5.1098)

Eisermann K, Wang D, Jing Y, Pascal LE \& Wang Z 2013 Androgen receptor gene mutation, rearrangement, polymorphism. Translational Andrology and Urology 2 137-147. (doi:10.3978/j.issn.22234683.2013.09.15)

Fijak M, Schneider E, Klug J, Bhushan S, Hackstein H, Schuler G, Wygrecka M, Gromoll J \& Meinhardt A 2011 Testosterone replacement effectively inhibits the development of experimental autoimmune orchitis in rats: evidence for a direct role of testosterone on regulatory $\mathrm{T}$ cell expansion. Journal of Immunology 186 5162-5172. (doi:10.4049/jimmunol.1001958)

Fijak M, Damm LJ, Wenzel JP, Aslani F, Walecki M, Wahle E, Eisel F, Bhushan S, Hackstein H, Baal N, et al. 2015 Influence of testosterone on inflammatory response in testicular cells and expression of transcription factor Foxp3 in T cells. American Journal of Reproductive Immunology 74 12-25. (doi:10.1111/aji.12363)

Fizazi K, Tran N, Fein L, Matsubara N, Rodriguez-Antolin A, Alekseev BY, Ozguroglu M, Ye D, Feyerabend S, Protheroe A, et al. 2017
Abiraterone plus prednisone in metastatic, castration-sensitive prostate cancer. New England Journal of Medicine 377 352-360. (doi:10.1056/NEJMoa1704174)

Flammiger A, Weisbach L, Huland H, Tennstedt P, Simon R, Minner S, Bokemeyer C, Sauter G, Schlomm T \& Trepel M 2013 High tissue density of FOXP3+ T cells is associated with clinical outcome in prostate cancer. European Journal of Cancer 49 1273-1279. (doi:10.1016/j.ejca.2012.11.035)

Furman D, Hejblum BP, Simon N, Jojic V, Dekker CL, Thiebaut R, Tibshirani RJ \& Davis MM 2014 Systems analysis of sex differences reveals an immunosuppressive role for testosterone in the response to influenza vaccination. PNAS 111 869-874. (doi:10.1073/ pnas.1321060111)

Graff JN, Alumkal JJ, Drake CG, Thomas GV, Redmond WL, Farhad M, Cetnar JP, Ey FS, Bergan RC, Slottke R, et al. 2016 Early evidence of anti-PD-1 activity in enzalutamide-resistant prostate cancer. Oncotarget 7 52810-52817. (doi:10.18632/oncotarget.10547)

Gravis G, Boher JM, Joly F, Soulie M, Albiges L, Priou F, Latorzeff I, Delva R, Krakowski I, Laguerre B, et al. 2016 Androgen deprivation therapy (ADT) plus Docetaxel versus ADT alone in metastatic non castrate prostate cancer: impact of metastatic burden and long-term survival analysis of the randomized phase 3 GETUG-AFU15 trial. European Urology 70 256-262. (doi:10.1016/j.eururo.2015.11.005)

Ho PC, Tang GW \& Lawton JW 1991 Lymphocyte subsets in patients with oestrogen deficiency. Journal of Reproductive Immunology 20 85-91. (doi:10.1016/0165-0378(91)90025-L)

Huggins C, Stevens R \& Hodges CV 1941 Studies on prostatic cancer: II. The effects of castration on advanced carcinoma of the prostate gland. Archives of Surgery 43 209-223. (doi:10.1001/ archsurg.1941.01210140043004)

James ND, de Bono JS, Spears MR, Clarke NW, Mason MD, Dearnaley DP, Ritchie AWS, Amos CL, Gilson C, Jones RJ, et al. 2017 Abiraterone for prostate cancer not previously treated with hormone therapy. New England Journal of Medicine 377 338-351. (doi:10.1056/ NEJMoa1702900)

Kantoff PW, Higano CS, Shore ND, Berger ER, Small EJ, Penson DF, Redfern CH, Ferrari AC, Dreicer R, Sims RB, et al. 2010 Sipuleucel-T immunotherapy for castration-resistant prostate cancer. New England Journal of Medicine 363 411-422. (doi:10.1056/NEJMoa1001294)

Kissick HT, Sanda MG, Dunn LK, Pellegrini KL, On ST, Noel JK \& Arredouani MS 2014 Androgens alter T-cell immunity by inhibiting T-helper 1 differentiation. PNAS 111 9887-9892. (doi:10.1073/ pnas.1402468111)

Kocar IH, Yesilova Z, Ozata M, Turan M, Sengul A \& Ozdemir I 2000 The effect of testosterone replacement treatment on immunological features of patients with Klinefelter's syndrome. Clinical and Experimental Immunology 121 448-452. (doi:10.1046/j.1365-2249.2000.01329.x)

Koh YT, Gray A, Higgins SA, Hubby B \& Kast WM 2009 Androgen ablation augments prostate cancer vaccine immunogenicity only when applied after immunization. Prostate 69 571-584. (doi:10.1002/ pros.20906)

Kwilas AR, Ardiani A, Dirmeier U, Wottawah C, Schlom J \& Hodge JW 2015 A poxviral-based cancer vaccine the transcription factor twist inhibits primary tumor growth and metastases in a model of metastatic breast cancer and improves survival in a spontaneous prostate cancer model. Oncotarget 6 28194-28210. (doi:10.18632/ oncotarget.4442)

Kwon ED, Drake CG, Scher HI, Fizazi K, Bossi A, van den Eertwegh AJ, Krainer M, Houede N, Santos R, Mahammedi H, et al. 2014 Ipilimumab versus placebo after radiotherapy in patients with metastatic castration-resistant prostate cancer that had progressed after docetaxel chemotherapy (CA184-043): a multicentre, randomised, double-blind, phase 3 trial. Lancet Oncology 15 700-712. (doi:10.1016/S1470-2045(14)70189-5)

Lin AA, Wojciechowski SE \& Hildeman DA 2010 Androgens suppress antigen-specific $\mathrm{T}$ cell responses and IFN-gamma production during

Published by Bioscientifica Ltc 
intracranial LCMV infection. Journal of Neuroimmunology 226 8-19. (doi:10.1016/j.jneuroim.2010.05.026)

Liu L, Wu L, Gao A, Zhang Q, Lv H, Xu L, Xie C, Wu Q, Hou P \& Shi B 2016 The influence of dihydrotestosterone on the development of Graves' disease in female BALB/c mice. Thyroid 26 449-457. (doi:10.1089/thy.2015.0620)

Liva SM \& Voskuhl RR 2001 Testosterone acts directly on CD4+ T lymphocytes to increase IL-10 production. Journal of Immunology $\mathbf{1 6 7}$ 2060-2067. (doi:10.4049/jimmunol.167.4.2060)

Lyons LS, Rao S, Balkan W, Faysal J, Maiorino CA \& Burnstein KL 2008 Ligand-independent activation of androgen receptors by Rho GTPase signaling in prostate cancer. Molecular Endocrinology 22 597-608. (doi:10.1210/me.2007-0158)

Madan RA, Gulley JL, Schlom J, Steinberg SM, Liewehr DJ, Dahut WL \& Arlen PM 2008 Analysis of overall survival in patients with nonmetastatic castration-resistant prostate cancer treated with vaccine, nilutamide, and combination therapy. Clinical Cancer Research 14 4526-4531. (doi:10.1158/1078-0432.CCR-07-5048)

McNeel DG, Smith HA, Eickhoff JC, Lang JM, Staab MJ, Wilding G \& Liu G 2012 Phase I trial of tremelimumab in combination with short-term androgen deprivation in patients with PSA-recurrent prostate cancer. Cancer Immunology, Immunotherapy 61 1137-1147. (doi:10.1007/s00262-011-1193-1)

Mercader M, Bodner BK, Moser MT, Kwon PS, Park ES, Manecke RG, Ellis TM, Wojcik EM, Yang D, Flanigan RC, et al. $2001 \mathrm{~T}$ cell infiltration of the prostate induced by androgen withdrawal in patients with prostate cancer. PNAS 98 14565-14570. (doi:10.1073/pnas.251140998)

Morse MD \& McNeel DG 2010 Prostate cancer patients on androgen deprivation therapy develop persistent changes in adaptive immune responses. Human Immunology 71 496-504. (doi:10.1016/j. humimm.2010.02.007)

Morse MD \& McNeel DG 2012 T cells localized to the androgendeprived prostate are TH1 and TH17 biased. Prostate 72 1239-1247. (doi:10.1002/pros.22476)

Myung JK, Banuelos CA, Fernandez JG, Mawji NR, Wang J, Tien AH, Yang YC, Tavakoli I, Haile S, Watt K, et al. 2013 An androgen receptor $\mathrm{N}$-terminal domain antagonist for treating prostate cancer. Journal of Clinical Investigation 123 2948-2960. (doi:10.1172/JCI66398)

Njar VC \& Brodie AM 2015 Discovery and development of Galeterone (TOK-001 or VN/124-1) for the treatment of all stages of prostate cancer. Journal of Medicinal Chemistry 58 2077-2087. (doi:10.1021/ jm501239f)

Olsen NJ \& Kovacs WJ 2001 Effects of androgens on T and B lymphocyte development. Immunologic Research 23 281-288. (doi:10.1385/IR:23:2-3:281)

Olsen NJ \& Kovacs WJ 2011 Evidence that androgens modulate human thymic T cell output. Journal of Investigative Medicine 59 32-35. (doi:10.2310/JIM.0b013e318200dc98)

Olsen NJ, Olson G, Viselli SM, Gu X \& Kovacs WJ 2001 Androgen receptors in thymic epithelium modulate thymus size and thymocyte development. Endocrinology 142 1278-1283. (doi:10.1210/endo.142.3.8032)

Olson BM, Johnson LE \& McNeel DG 2013 The androgen receptor: a biologically relevant vaccine target for the treatment of prostate cancer. Cancer Immunology, Immunotherapy 62 585-596. (doi:10.1007/ s00262-012-1363-9)

Page ST, Plymate SR, Bremner WJ, Matsumoto AM, Hess DL, Lin DW, Amory JK, Nelson PS \& Wu JD 2006 Effect of medical castration on CD4+ CD25+ T cells, CD8+ T cell IFN-gamma expression, and NK cells: a physiological role for testosterone and/or its metabolites. American Journal of Physiology - Endocrinology and Metabolism 290 E856-E863. (doi:10.1152/ajpendo.00484.2005)

Pfeiffer MJ, Smit FP, Sedelaar JP \& Schalken JA 2011 Steroidogenic enzymes and stem cell markers are upregulated during androgen deprivation in prostate cancer. Molecular Medicine 17 657-664. (doi:10.1007/s00894-010-0756-y)
Pierdominici M, Maselli A, Colasanti T, Giammarioli AM, Delunardo F, Vacirca D, Sanchez M, Giovannetti A, Malorni W \& Ortona E 2010 Estrogen receptor profiles in human peripheral blood lymphocytes. Immunology Letters 132 79-85. (doi:10.1016/j.imlet.2010.06.003)

Prieto GA \& Rosenstein Y 2006 Oestradiol potentiates the suppressive function of human CD4 CD25 regulatory T cells by promoting their proliferation. Immunology 118 58-65. (doi:10.1111/j.1365-2567.2006.02339.x)

Pu Y, Xu M, Liang Y, Yang K, Guo Y, Yang X \& Fu YX 2016 Androgen receptor antagonists compromise $\mathrm{T}$ cell response against prostate cancer leading to early tumor relapse. Science Translational Medicine $\mathbf{8}$ 333ra347. (doi:10.1126/scitranslmed.aad5659)

Roden AC, Moser MT, Tri SD, Mercader M, Kuntz SM, Dong H, Hurwitz AA, McKean DJ, Celis E, Leibovich BC, et al. 2004 Augmentation of $\mathrm{T}$ cell levels and responses induced by androgen deprivation. Journal of Immunology 173 6098-6108. (doi:10.4049/ jimmunol.173.10.6098)

Sanda MG, Smith DC, Charles LG, Hwang C, Pienta KJ, Schlom J, Milenic D, Panicali D \& Montie JE 1999 Recombinant vaccinia-PSA (PROSTVAC) can induce a prostate-specific immune response in androgen-modulated human prostate cancer. Urology 53 260-266. (doi:10.1016/S0090-4295(98)00539-1)

Sandford NL, Searle JW \& Kerr JF 1984 Successive waves of apoptosis in the rat prostate after repeated withdrawal of testosterone stimulation. Pathology 16 406-410. (doi:10.3109/00313028409084731)

Schweizer MT, Wang H, Luber B, Nadal R, Spitz A, Rosen DM, Cao H, Antonarakis ES, Eisenberger MA, Carducci MA, et al. 2016 Bipolar androgen therapy for men with androgen ablation naive prostate cancer: results from the phase II BATMAN study. Prostate $\mathbf{7 6}$ 1218-1226. (doi:10.1002/pros.23209)

Sciarra A, Abrahamsson PA, Brausi M, Galsky M, Mottet N, Sartor O, Tammela TL \& Calais da Silva F 2013 Intermittent androgendeprivation therapy in prostate cancer: a critical review focused on phase 3 trials. European Urology 64 722-730. (doi:10.1016/j. eururo.2013.04.020)

Sheikh NA, Petrylak D, Kantoff PW, Dela Rosa C, Stewart FP, Kuan LY Whitmore JB, Trager JB, Poehlein CH, Frohlich MW, et al. 2013 Sipuleucel-T immune parameters correlate with survival: an analysis of the randomized phase 3 clinical trials in men with castrationresistant prostate cancer. Cancer Immunology, Immunotherapy 62 137-147. (doi:10.1007/s00262-012-1317-2)

Shiota M, Itsumi M, Takeuchi A, Imada K, Yokomizo A, Kuruma H, Inokuchi J, Tatsugami K, Uchiumi T, Oda Y, et al. 2015 Crosstalk between epithelial-mesenchymal transition and castration resistance mediated by Twist1/AR signaling in prostate cancer. Endocrine-Related Cancer 22 889-900. (doi:10.1530/ERC-15-0225)

Siegel RL, Miller KD \& Jemal A 2016 Cancer statistics, 2016. CA: A Cancer Journal for Clinicians 66 7-30. (doi:10.3322/caac.21332)

Small EJ, Lance RS, Gardner TA, Karsh LI, Fong L, McCoy C, DeVries T, Sheikh NA, GuhaThakurta D, Chang N, et al. 2015 A randomized phase II trial of sipuleucel-T with concurrent versus sequential abiraterone acetate plus prednisone in metastatic castration-resistant prostate cancer. Clinical Cancer Research 21 3862-3869. (doi:10.1158/1078-0432.CCR-15-0079)

Stimson WH 1988 Oestrogen and human T lymphocytes: presence of specific receptors in the T-suppressor/cytotoxic subset. Scandinavian Journal of Immunology 28 345-350. (doi:10.1111/j.1365-3083.1988. tb01459.x)

Sutherland JS, Goldberg GL, Hammett MV, Uldrich AP, Berzins SP, Heng TS, Blazar BR, Millar JL, Malin MA, Chidgey AP, et al. 2005 Activation of thymic regeneration in mice and humans following androgen blockade. Journal of Immunology 175 2741-2753. (doi:10.4049/jimmunol.175.4.2741)

Sutherland JS, Spyroglou L, Muirhead JL, Heng TS, Prieto-Hinojosa A, Prince HM, Chidgey AP, Schwarer AP \& Boyd RL 2008 Enhanced 
immune system regeneration in humans following allogeneic or autologous hemopoietic stem cell transplantation by temporary sex steroid blockade. Clinical Cancer Research 14 1138-1149. (doi:10.1158/1078-0432.CCR-07-1784)

Tang S, Moore ML, Grayson JM \& Dubey P 2012 Increased CD8+ T-cell function following castration and immunization is countered by parallel expansion of regulatory T cells. Cancer Research $\mathbf{7 2}$ 1975-1985. (doi:10.1158/0008-5472.CAN-11-2499)

Teo MY \& Scher HI 2015 CHAARTED/GETUG 12--docetaxel in noncastrate prostate cancers. Nature Reviews: Clinical Oncology 12 687-688. (doi:10.1038/nrclinonc.2015.192)

Topalian SL, Hodi FS, Brahmer JR, Gettinger SN, Smith DC, McDermott DF, Powderly JD, Carvajal RD, Sosman JA, Atkins MB, et al. 2012 Safety, activity, and immune correlates of anti-PD-1 antibody in cancer. New England Journal of Medicine 366 2443-2454. (doi:10.1056/NEJMoa1200690)

Valor L, Teijeiro R, Aristimuno C, Faure F, Alonso B, de Andres C, Tejera M, Lopez-Lazareno N, Fernandez-Cruz E \& Sanchez-Ramon S 2011 Estradiol-dependent perforin expression by human regulatory T-cells. European Journal of Clinical Investigation 41 357-364. (doi:10.1111/j.1365-2362.2010.02414.x)

Velardi E, Tsai JJ, Holland AM, Wertheimer T, Yu VW, Zakrzewski JL, Tuckett AZ, Singer NV, West ML, Smith OM, et al. 2014 Sex steroid blockade enhances thymopoiesis by modulating Notch signaling.
Journal of Experimental Medicine 211 2341-2349. (doi:10.1084/ jem.20131289)

Visakorpi T, Hyytinen E, Koivisto P, Tanner M, Keinanen R, Palmberg C, Palotie A, Tammela T, Isola J \& Kallioniemi O-P 1995 In vivo amplification of the androgen receptor gene and progression of human prostate cancer. Nature Genetics 9 401-406. (doi:10.1038/ng0495-401)

Walecki M, Eisel F, Klug J, Baal N, Paradowska-Dogan A, Wahle E, Hackstein H, Meinhardt A \& Fijak M 2015 Androgen receptor modulates Foxp3 expression in CD4+CD25+Foxp3+ regulatory T-cells. Molecular Biology of the Cell 26 2845-2857. (doi:10.1091/mbc. E14-08-1323)

Weinstein Y, Ran S \& Segal S 1984 Sex-associated differences in the regulation of immune responses controlled by the MHC of the mouse. Journal of Immunology 132 656-661.

Whitacre CC 2001 Sex differences in autoimmune disease. Nature Immunology 2 777-780. (doi:10.1038/ni0901-777)

Yamashita S, Lai K-P, Chuang K-L, Xu D, Miyamoto H, Tochigi T, Pang S-T, Li L, Arai Y, Kung H-J, et al. 2012 ASC-J9 suppresses castrationresistant prostate cancer growth through degradation of full-length and splice variant androgen receptors. Neoplasia 14 74-IN12.

Yu Z, Cai C, Gao S, Simon NI, Shen HC \& Balk SP 2014 Galeterone prevents androgen receptor binding to chromatin and enhances degradation of mutant androgen receptor. Clinical Cancer Research 20 4075-4085. (doi:10.1158/1078-0432.CCR-14-0292)

Received in final form 11 August 2017

Accepted 16 August 2017

Accepted preprint published online 16 August 2017
(C) 2017 Society for Endocrinology Printed in Great Britain
Published by Bioscientifica Ltd. 